\title{
Madrinas del franquismo. La Sección Femenina de Falange en Granada durante la Guerra Civil (1936-1939)
}

\section{Godmothers of Francoism. The Sección Femenina of Falange in Granada during the Spanish Civil War (1936-1939)}

\author{
FRANCISCO JIMÉNEZ AGUILAR \\ Universidad de Granada \\ fjja@correo.ugr.es
}

\begin{abstract}
Resumen: El presente artículo pretende analizar la movilización femenina fascista y los instrumentos que la posibilitaron a través del estudio de la Sección Femenina de Falange durante la Guerra Civil española. Por medio del estudio del caso de la provincia de Granada podremos acercarnos a cifrar el impacto que esta tuvo y debatir sobre su peso en la consecución de los objetivos franquistas durante los años que duró la contienda. Esto nos permitirá observar cómo un cada vez mayor número de españolas pudieron participar activamente en el conflicto, teniendo un papel notable dentro de la organización falangista en el apoyo material, médico y moral de la victoria militar sublevada y en la cimentación de las políticas sociales y de la mujer del Estado franquista.
\end{abstract}

Palabras Clave: Andalucía, fascismo, Guerra Civil, mujer, Sección Femenina de Falange.

Abstract: This article aims to analyse the female fascist mobilization and the devices that enabled it possible through the study of the Sección Femenina of Falange during the Spanish Civil War. By studying the case of the province of Granada we might approach to relate the impact that it had and to discuss its weight in order to achieve the francoist objectives during these years. This will allow us to observe how an increasing number of Spanish women were able to actively participate in the conflict, having a noteworthy role within the falangist organization in the moral, medical, and material support of the rebels' military victory and in the foundation of feminine and social policies under francoist state.

Keywords: Andalusia, Fascism, Spanish Civil War, women, Sección Femenina of Falange.

Recibido: 20 de octubre de 2016; aceptado: 9 de enero de 2017; publicado: 21 de septiembre de 2017. Revista Historia Autónoma, 11 (2017), pp. 199-218. 


\section{Introducción}

En pleno desarrollo de la contienda, desde la prensa de derechas se reconocía que

"si grande es el abismo que separa las dos concepciones de la vida en la zona roja y en la zona nacional, acaso sea este aspecto de la mujer — función que tiene asignada, misión que desempeña — uno de los que marcan las diferencias más hondas e irreducibles entre la España legítima y la que detentan nuestros adversarios"

Para el embrionario "Nuevo Estado" de Franco la cuestión de género no era un asunto menor y la propaganda de estos años da buena fe de ello. Esto nos lleva a plantearnos hacia dónde se dirigía este tipo de discursos y cuál era la importancia que desde el régimen se le daba a dirigir y dotar de sentido a la participación femenina. No cabe duda de que dentro de esa "concepción de la vida" el cometido de la mujer estaba orientado hacia las necesidades que generaba el estado de excepción que supuso la Guerra Civil: lugar de confluencia de desafíos y proyectos políticos. Pero, también, a esas visiones republicanas de la nación que a través de la violencia ilegítima se pretendían impugnar. Así pues, todo esto sirvió para que muchas mujeres experimentaran nuevas obligaciones y prácticas en la esfera pública y privada que irían perfilando sus vidas en los años posteriores.

El objetivo de este artículo es el de mostrar cómo la Guerra Civil propició la movilización de las mujeres del espectro derechista en la esfera pública desde una perspectiva local y regional. Este contexto beligerante favoreció que muchas españolas decidieran tomar parte desde diferentes organizaciones políticas ofreciendo una ayuda que fue destacable para que el Estado sublevado finalmente venciera. Luego, forzosamente, tuvo secuelas modernizadoras, reaccionarias, continuistas y novedosas dentro del proceso de transformación de las relaciones de género que se estaba dando en la Europa de entreguerras y que, más tarde, se daría durante el franquismo.

El estudio de la movilización fascista de las mujeres había sido enfrentado en un primer momento de forma reduccionista por la historiografía, al caracterizarla como un fenómeno producido por la lógica represiva de los movimientos y regímenes fascistas que unívocamente devolvía a las mujeres a una posición de "ciudadanas de segunda". Pese a que esta visión tuvo una amplia aceptación, se ha venido debatiendo y mostrando el hecho de que las motivaciones y actitudes de las mujeres tras la sombra del fascismo fueron mucho más heterogéneas de lo que se había creído². Esto ha permitido vislumbrar que, en primer lugar, los apoyos de algunas

\footnotetext{
${ }^{1}$ Ideal, 18 de julio de 1937, p. 17.

${ }^{2}$ En torno al debate sobre la movilización y participación de la mujer bajo los fascismos véase: Koonz, Claudia, Mothers in the Fatherland: Women, the Family and Nazi Politics, Nueva York, Saint Martin's Press, 1987; Grosmann, Atina, "Feminist Debates about Women and Nacional Socialism", en Gender \& History, 3 (1991),
} 
mujeres al fascismo solían poseer un carácter reflexivo y voluntario. En segundo lugar, estos estaban condicionados por una compleja multiplicidad de factores que "desde abajo", mediante elementos ideológicos, económicos y culturales, y “desde arriba”, a través de políticas inclusivas, cohesivas y legitimadoras, propiciaban la participación femenina en la esfera pública. Por último, estos provocaron transformaciones importantes tanto para la continuidad, la liberación y la relativa ampliación de la agencia femenina, como para la creación y reproducción de contingencias capaces de sustentar la condición subordinada de la mujer bajo las relaciones de dominación masculina. Tensión que propiciaría que se diesen como en otros países ciertas experiencias y progresos feministas en pos de la igualdad de género, especialmente bajo el marco de la guerra ${ }^{3}$, pero que estos estuviesen en cierta medida controlados, neutralizados y fueran frecuentemente truncados con el fin de perpetuar la posición subalterna de la mujer ${ }^{4}$.

Aunque la España de la década de los treinta podría servir como muestra nacional de una mayor obtención de derechos y libertades e integración política de las mujeres, al lograrse obtener el voto en 1931 y empezar a desempeñar cargos públicos, fue al mismo tiempo testigo de amplias reacciones antifeministas 5 . Si bien de izquierda a derecha, y con la irrupción de los partidos fascistas, se hizo evidente la necesidad de movilizar a las mujeres, comenzando por algunos partidos de derecha con un mayor recorrido como Acción Católica o la Comunión Tradicionalista Carlista, donde muchas mujeres se incorporaron rápidamente a la vida pública, hasta la organización política que acabaría alcanzando más adelante la hegemonía de la movilización femenina en la contienda y el franquismo: la Sección Femenina de Falangé.

Igualmente, cabe destacar que no ha sido hasta hace pocos años cuando los historiadores han tenido en cuenta el rol que jugaron las mujeres en el desarrollo del conflicto armado, especialmente en el caso de las mujeres de derechas. Pese a las críticas que ha despertado, trabajos recientes como el de Michael Seidman han puesto de relieve la importancia de la actividad asistencialista que llevaron a cabo las mujeres falangistas en relación con el esfuerzo

pp. 350-358; Gottlieb, Julie, Feminine Fascism. Women in Fascist's Britain Movement, 1923-1945, Londres, I. B. Tauris, 2000; Rodríguez López, Sofía, El patio de la cárcel: la Sección Femenina de FET-JONS en Almería (19371977), Sevilla, Centro de Estudios Andaluces, 2010, pp. 83-87.

${ }^{3}$ Tavera, Susanna, "«Las mujeres y las guerras»: aspectos de una temática heterogénea”, en Journal of Feminist, Gender and Women Studies, 3 (2016), pp. 21-29.

${ }^{4}$ Sobre estas cuestiones en el caso de España han escrito: Enders, Victoria, "Problematic Portraits: The Ambiguous Historical Role of the Sección Femenina of the Falange", en Enders, Victoria y Pamela Radcliff, Constructing Spanish Womanhood: Female Identity In Modern Spain, Albany, Sate University of New York Press, 1999, pp. 375-397; Cenarro, Ángela, "Movilización femenina para la guerra total (1936-1939). Un ejercicio comparativo", en Historia y Politica, 16 (2006), pp. 159-182; Prada, Julio, “"Mujeres contra la revolución»: La movilización femenina conservadora durante la Segunda República española y la Guerra Civil”, en Amnis, 8 (2008). «https:// amnis.revues.org/ 599\#ftn2» [consultado el 4 de octubre de 2016].

${ }^{5}$ Sintetizado recientemente en: González Calleja, Eduardo et al., La Segunda República española, Barcelona, Pasado \& Presente, 2015, pp. 130-143.

${ }^{6}$ A nivel regional y local la cuestión de la movilización ha sido tratada en: Jarne, Antonieta, La Secció Femenina a Lleida. Els anys "triomfals", Lleida, Pages Editors, 1991; Blasco, Inmaculada, Armas femeninas para la contrarrevolución: la Sección femenina en Aragón (1936-1950), Málaga, Atenea, 1999; Rodríguez López, Sofía, El patio... op. cit.; Marías, Secún, "Por España y por el campo": la Sección Femenina en el medio rural oscense (1933-1977), Huesca, Instituto de Estudios Altoaragoneses, 2011. 
bélico franquista ${ }^{7}$. Sin embargo, debemos de matizar al menos dos aspectos de sus aportaciones. Por un lado, este apoyo fue al mismo tiempo dirigido a otras actividades diferentes de la asistencia, como la educación básica y la formación laboral de la mujer o la elaboración de elementos propagandísticos. Por otro lado, su actuación debe ser puesta en relación con la trayectoria de la organización y las necesidades políticas de cada momento, desde que en 1934 fuera fundada hasta después de la derrota republicana. El esfuerzo de la Sección Femenina, más allá de ganar la guerra, estaba también orientado a la construcción del nuevo régimen franquista y a la sujeción de la mujer en su interior.

Para poder examinar las problemáticas de la movilización y actuación de la Sección Femenina, este artículo se basa en un estudio de caso de la provincia de Granada. Este espacio, pese a que su capital quedase sometida a la España sublevada a los pocos días del golpe de Estado del 18 de julio, presenta distintos ritmos de sumisión a esta e interesantes contrastes entre el ámbito urbano y, sobre todo, rural que la caracteriza. Para abordarlo, nos hemos valido de diversas fuentes primarias: fuentes procedentes de archivos locales y provinciales que arrojan información sobre las instituciones locales durante la Guerra Civil; otras pertenecientes a la propia Sección Femenina a nivel regional y nacional que nos permiten observar su constitución, sus transformaciones y sus tareas; y fuentes hemerográficas de la época que nos ayudan a contrastar y criticar el discurso construido en torno a estas mujeres y su participación política; además de contar con la abundante bibliografía de época y actual sobre estos temas. Todo esto nos permitirá, en un primer apartado, analizar los instrumentos políticos, institucionales y culturales utilizados por el franquismo para incrementar la movilización femenina falangista y criticar los efectos reales que estos tuvieron. Inmediatamente después, nos adentraremos en un segundo apartado en torno a la organización y los ámbitos de acción que poseyó la Sección Femenina a lo largo de estos años con el propósito de caracterizar su papel durante la contienda.

\section{La movilización falangista femenina durante la Guerra Civil}

Una vez estalló la Guerra Civil, la Sección Femenina de Falange pudo observar cómo empezaron a recabar más afiliadas. El contexto bélico justificó que las mujeres irrumpieran en la esfera pública con miras a defender el proyecto nacional sublevado. Sus condicionantes socioeconómicos, sus deseos e intereses, sus convicciones ideológicas o sus miedos al enfrentamiento armado motivaron que cada vez más mujeres tomaran parte en la contienda y en la construcción de la Nueva España. Según exponía Ideal, de las 2500 mujeres afiliadas

\footnotetext{
${ }^{7}$ Seidman, Michael, The Victorious Contrarrevolution: The Nationalist Effort in the Spanish Civil War, Madison, University of Wisconsin Press, 2011.
} 
a la Sección Femenina que había en toda España antes del 18 de julio de 1936, se alcanzó la controvertida cantidad de 600000 afiliadas para el año 1939.

Gráfico 1: Afiliadas a la Sección Femenina de Falange en toda España (1934-1939)

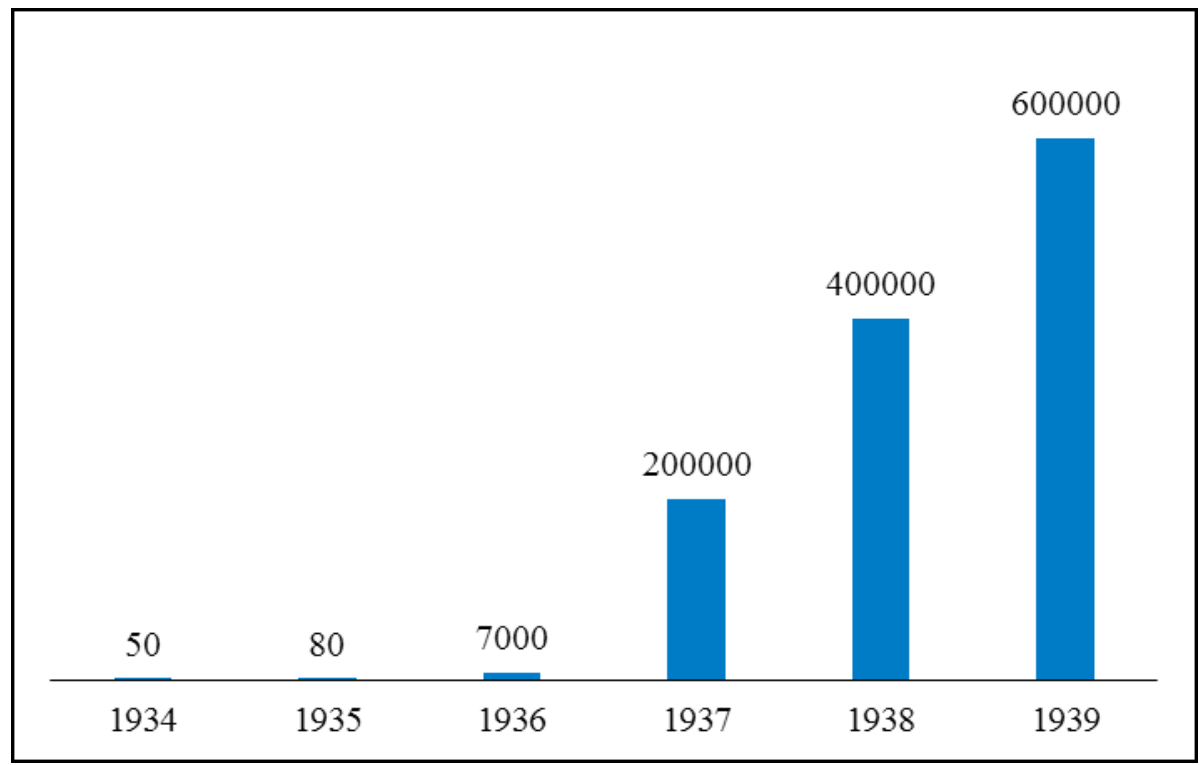

Fuente: elaboración propia a partir de Ideal, 9 de enero de 1942, p. 6.

A la hora de analizar la movilización femenina a través de la Sección Femenina, la historiadora Sofía Rodríguez ha diferenciado dos principales etapas de afiliación tras darse el golpe de Estado: la afiliación de "muerte" y la de "victoria". La afiliación de "muerte" correspondería a la primera gran etapa de movilización femenina bajo signo falangista provocada por la Guerra Civil (1936-19398). La consolidación política y social de la sublevación en determinadas localidades y regiones empujó a muchas mujeres a tomar directamente parte por medio de organizaciones de mujeres como la Sección Femenina, que desempeñaba numerosas tareas asistenciales, educativas y logísticas en amparo de la población, el ejército y el Estado sublevado. En cambio, la afiliación de "victoria" sería la segunda etapa engendrada al final de la contienda, a partir de 1939, al quedar toda España sometida bajo control franquista. En este tiempo pudo verse parte de los efectos movilizadores, nacionalizadores, catolizadores y compensatorios con las "vencedoras" que la posguerra y el triunfo de su "Cultura de la Victoria" tuvo para muchas mujeres. Con la derrota de la República, se reafirmó el compromiso de las pocas que demostraron que habían apoyado el "Alzamiento" desde la zona republicana o de las que se habían quedado en sus hogares sin participar, a la par que se movió a las que se encontraban en la "zona gris" a participar para mostrar adhesión o para sobrevivir. La afiliación de muerte en Andalucía se daría en casos como el granadino, malagueño o sevillano, que fueron

\footnotetext{
${ }^{8}$ Rodríguez López, Sofía, El patio... op. cit., pp. 52-65.

${ }^{9}$ Hernández Burgos, Claudio, Granada Azul. La construcción de la "Cultura de la Victoria" en el primer franquismo, 1936-1951, Granada, Comares, 2011.
} 
regiones que desde un primer momento, o al poco tiempo de iniciarse la guerra, quedaron sometidas. En tanto que la afiliación sería de victoria en Almería o Jaén al experimentar el "entusiasmo" de los primeros días de posguerra.

En 1939 la Delegación Provincial granadina, dirigida por María Teresa Jaén Botella, contaba con la cifra de 1632 mujeres en la ciudad y más de 10000 en toda la provincia entre afiliadas y "flechas femeninas" menores de edad de acuerdo con la prensa. ${ }^{10}$ A partir de los datos que poseemos sobre Granada capital se puede observar cómo la evolución de la afiliación debe más a las consecuencias de "muerte" que a las de "victoria". Granada, bajo signo sublevado desde los primeros días, pudo ver a lo largo de este año cómo se iban sumando 580 mujeres hasta llegar a las 643. Esta cantidad creció en 627 afiliadas más en 1937 (año marcado por la unificación política en FET de las JONS) y aún continuó en aumento aunque con menor fuerza con la afiliación de 235 y 127 mujeres más en 1938 y 1939, respectivamente, lo que muestra una moderación de la movilización femenina.

Gráfico 2: Afiliadas a la Sección Femenina de Falange en la ciudad de Granada (1936-1939)

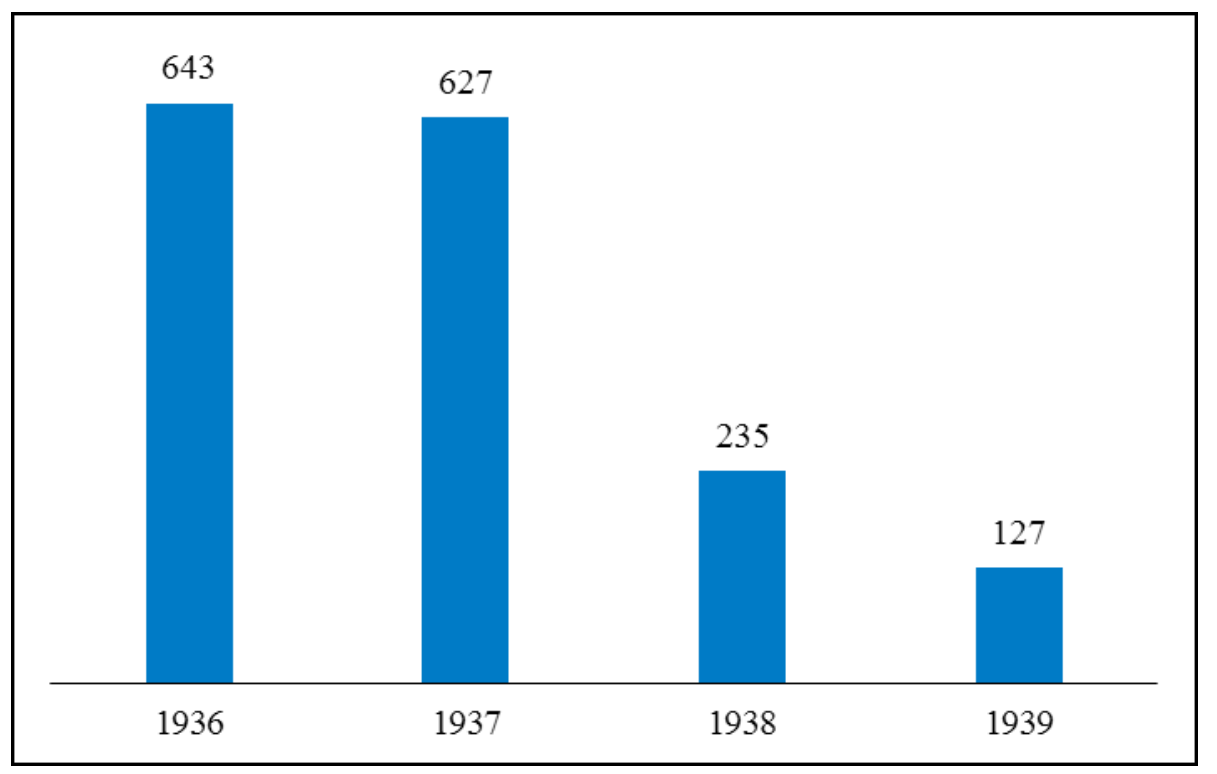

Fuente: elaboración propia a partir de Archivo Histórico Provincial de Granada [en adelante, AHPG], "Historia de la Sección Femenina del Movimiento: Granada”, sig. 3167-1.

No obstante, la creciente afiliación de "muerte" no se dio de modo homogéneo en toda la provincia. Gran parte de los pueblos de la provincia siguieron ritmos de afiliación similares a los de la capital conforme las líneas del frente iban avanzando y se iban constituyendo nuevas secciones femeninas. Destacan entre ellos importantes municipios como Montefrío, Órgiva, Dúrcal o Íllora. En contraste con ellos, otros municipios presentaron una afiliación más tardía 
de "victoria" debido a su postrero sometimiento, a la incapacidad logística de las instituciones franquistas para organizarlas o a la falta de apoyos sociales ${ }^{11}$. Si nos valemos de las cifras que nos ofrecen los listados de realización del Servicio Social podemos apreciar que la movilización de la mujer es mucho mayor a partir de 1939 en algunos pueblos de la provincia. Principalmente la afiliación de "victoria" se dio en pueblos de las comarcas nordestes como Baza (con 34 cumplidoras), Caniles (28) o Huéscar (21), que fueron los últimos en ser "liberados" por los ejércitos franquistas, y en otros como Guadix (12), las Gabias (16) o Ventas de Zafarraya (8) que tardarían en desarrollar sus secciones femeninas locales debido a la falta de adhesión o a carencias materiales y problemas logísticos ${ }^{12}$. Por ello, el desarrollo de la Sección Femenina a nivel provincial fue heterogéneo en el tiempo y en el espacio, marcado por el alcance del desarrollo bélico y por las propias particularidades sociopolíticas locales.

Granada y los pueblos que quedaron bajo control sublevado requirieron de una creciente participación femenina en la retaguardia para apoyar al frente y para que no se quebrara el equilibrio social a causa de las terribles consecuencias del conflicto. Pese a las numerosas causas que podríamos enumerar, podemos destacar tres factores para entender la creciente movilización femenina falangista: primero, la paulatina creación de un "culto a la feminidad falangista"; segundo, la parcial agrupación e inclusión en la Sección Femenina de las organizaciones femeninas católicas y de las otras derechas; tercero, la creación de nuevos instrumentos de movilización femenina como el Servicio Social. Todos estos permitieron una mayor movilización y cohesión femenina en pos de sostener al régimen sublevado.

\subsection{El culto a la feminidad falangista}

Con el fin de movilizar a las mujeres, se pusieron en funcionamiento todos los instrumentos ideológicos con los que se contaba para reproducir discursos exhortadores, de tintes realistas y heroicos, sobre la necesaria labor de la mujer en la retaguardia franquista. Desde la prensa local, pasando por la radio ${ }^{13} \mathrm{o}$ las revistas orientadas a un público femenino ${ }^{14}$, hasta el púlpito de la iglesia sirvieron para reproducir una idea de mujer y de los deberes "compatibles con su sexo" que esta tenía ante las acuciantes necesidades del "Nuevo Estado". Se creó por ello un "culto" a un tipo de feminidad cimentada entre discursos, imágenes y símbolos destinados a obtener el apoyo de muchas mujeres ${ }^{15}$. Se consiguió con ello una mayor afiliación a la Sección Femenina y el comienzo de la nueva ordenación y modulación franquista de las actitudes de las mujeres.

\footnotetext{
${ }_{11}$ AHPG, "Historia de la..." op. cit.

${ }^{12}$ AHPG, "Servicio Social Obligatorio, 1938-1958", sig. 8422.

${ }^{13}$ Pérez Martínez, José Emilio, "Mujeres en la radio española del siglo xx (1924-1989)", en Arenal, vol. 23, 1 (2016), pp. 44-45.

${ }^{14}$ Rubio Liniers, María Cruz y María del Rosario Ruiz Franco, "Presencia, participación e ideología de las mujeres en la guerra civil española a través de dos revistas: Mujeres Libres e Y. Revista para la mujer", en Nash, Mary y Susanna Tavera (coords.), Las mujeres y las guerras: el papel de las mujeres en las guerras de la Edad Antigua a la Contemporánea, Barcelona, Icaria, 2003, pp. 502-525.

${ }^{15}$ Sobre el concepto de "culto a la feminidad": Blasco, Inmaculada, Armas femeninas ... op. cit., pp. 44-53. Véase también: Richmond, Kathleen, Las mujeres en el fascismo español: la Sección Femenina de la Falange, 19341959, Madrid, Alianza Editorial, 2004, pp. 71-104.
} 
Por un lado, este culto reprochaba la impasibilidad y la falta de iniciativa de las mujeres. Para el falangismo ellas debían responder ante su nación y sus hombres ${ }^{16}$ : "Y tú, ¿cuántas prendas les has llevado, cuantos sacrificios te has impuesto, para ofrecerles algún alivio, alguna mejora?... Ellos, los que luchan, no piensan, no anhelan, ni sueñan con otra cosa, hasta dar su vida, que por el bien de la Patria" ${ }^{17}$. Todas ellas tenían total responsabilidad de sus acciones y por ello debían participar de algún modo desde sus hogares o al unirse a la Sección Femenina. Cada acción, cada tarea, cada comedimiento tenía un efecto y un significado para la causa nacional y para el propio colectivo de las mujeres falangistas, responsables, en ultima instancia, de la organización de su acción, como señalaba Pilar Primo de Rivera: "En nuestras manos está el conseguir que no se diga que a la mujeres de Granada nos falta espíritu. ¿Dejaremos que esto se llegue a decir?" 18.

Por otro lado, se encomiaba y ensalzaba el valor de la labor femenina. Las mujeres en sí, pero especialmente las afiliadas de la Sección Femenina ${ }^{19}$, su carácter falangista y sus atributos femeninos eran poderosamente adjetivados, elogiados y potenciados ${ }^{20}$. A la vez que se consideraba que su labor transformaba y deificaba a la mujer en una "España [que] exige sacrificios múltiples: dinero, esfuerzos, vidas y, sobre todo, buenos corazones" ${ }^{21}$. Dentro de estos discursos cada aspecto del quehacer femenino era imprescindible, meritorio o eficaz. Además, para ello, se valían de símbolos y figuras femeninas ejemplarizantes. Personajes históricos y religiosos como Isabel la Católica, Santa Teresa de Jesús y otros contemporáneos servían de modelos de feminidad a imitar pues, a ojos del falangismo, reunían todos los "valores" considerados indispensables para guiar las prácticas femeninas ${ }^{22}$.

Este "culto a la feminidad" soportaba la necesidad del Estado y el partido de demandar el apoyo de las mujeres. Pero también, en última instancia, servía para justificar simbólicamente una lenta mutación de la posición de estas en el espacio público. Mientras se ensalzaba y extendía un modelo de mujer falangista, se neutralizaba y reprimía la agencia femenina conquistada, deslegitimándose y suprimiéndose muchos de los derechos y de los cambios en las actitudes de las mujeres conseguidos hasta el final de la Segunda República. Así se podrían aprovechar algunas de las transformaciones en las prácticas de las mujeres, como su mayor implicación en algunos aspectos laborales y de la esfera pública, mientras se aumentaba por otros medios la sumisión de estas al hombre y al Estado franquista ${ }^{23}$.

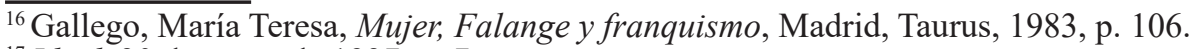

${ }^{17}$ Ideal, 30 de enero de 1937, p. 7.

${ }^{18}$ Ideal, 5 de septiembre de 1937, p. 11.

${ }^{19}$ Ofer, Inbal, "A «New» Woman for a «New» Spain: The Sección Femenina de la Falange and the Image of the National Syndicalist Woman", en European History Quarterly, vol. 39, 4 (2009), p. 590. DOI: https://doi. org/10.1177/0265691409342657.

${ }^{20}$ Ideal, 5 de junio de 1937, p. 6 y 18 de julio de 1937, p. 17.

${ }^{21}$ Ideal, 22 de febrero de 1937 , p. 3.

${ }^{22}$ Ofer, Inbal, "Historical Models, Contemporary Identites: The Sección Femenina of the Spanish Falange and its Redefinition of the Term «Feminity»", en Journal of Contemporary History, vol. 40, 4 (2005), pp. 663-674. DOI: https://doi.org/10.1177/0022009405056123.

${ }_{23}^{23}$ Moraga, María Ángeles, "Notas sobre la situación jurídica de la mujer en el franquismo", en Feminismo/s, 12 (2008), pp. 229-252.
} 


\subsection{La unificación de las secciones femeninas}

Durante la Guerra Civil también se consiguió unificar parcialmente a gran parte de las organizaciones femeninas de derechas bajo Falange al constituirse esta en abril de 1937 como el "Partido Único". Desde su inicio la Sección Femenina Carlista, Acción Católica o Auxilio de Invierno trabajaron por su cuenta apoyando bajo diferente signo político al "Nuevo Estado". De este modo, labores como la asistencia material y médica en el frente o el avituallamiento a la población azotada por la falta de recursos carecían de una cohesión organizativa y práctica, lo cual resultaba un obstáculo para constituir la organización femenina que el proyecto totalizador de Falange abanderaba.

Indudablemente, la fusión de los partidos de 1937 tuvo sus efectos en las políticas sobre la mujer y las organizaciones femeninas que quedaron en su mayoría agrupadas dentro de la Sección Femenina de Falange. Aunque este hecho podía suponer una mayor adhesión y cohesión que beneficiaría a la acción de la Sección Femenina, no fue en un primer momento percibido por Pilar Primo de Rivera y su entorno como positivo. Pese a que el objetivo era ganar la guerra, la colaboración de otras mujeres con diferente ideología era advertida como un problema fuertemente desvirtuador del proyecto falangista que quería desarrollarse ${ }^{24}$.

Si analizamos finalmente los resultados de la "Unificación femenina" podemos observar que, aunque tuviese consecuencias importantes, nunca llegó a materializarse por completo. Las divisiones existentes se dieron interna y externamente, los conflictos que encadenaba Pilar Primo de Rivera con otras líderes o con el propio partido por atesorar todo el poder sobre las mujeres nos ofrecen buenos testimonios de ello. En consecuencia, hasta el final de la contienda y después de esta se pueden apreciar las diferencias ideológicas y prácticas en la Sección Femenina entre los falangismos madrileño y jonsista, el nacionalcatolicismo y el tradicionalismo carlista ${ }^{25}$.

En primer lugar, muchas de las mujeres que pasaron a la Sección Femenina mantuvieron su posicionamiento ideológico y no realizaron una adhesión completa o real al falangismo ${ }^{26}$. Por ejemplo, paralelamente a la nueva organización impuesta por las jefas nacionales, provinciales y locales, las "margaritas carlistas" granadinas, mantuvieron su identidad política durante gran parte de la Guerra Civil al diferenciar sus hospitales de los falangistas o al asistir unidas a eventos ligados a su pasado como fue la visita de la dirigente tradicionalista María Rosa Urraca Pastor, en ese momento al mando del Delegación Nacional de Asistencia al Frente y Hospitales ${ }^{27}$.

En segundo lugar, en favor de los sectores más católicos se permitió que continuasen actuando independientemente organizaciones como Acción Católica y otras en las que

\footnotetext{
${ }^{24}$ Gallego, María Teresa, Mujer, falange... op. cit., pp. 47-79; Sánchez Blanco, Laura y Eulalia Torrubia, "Conflictos en la retaguardia nacional: Sección Femenina, Auxilio Social y Frente de Hospitales en la Guerra Civil española", en Prieto Borrego, Lucía (ed.), Encuadramiento femenino, socialización y cultura en el franquismo, Málaga, Universidad de Málaga, 2010, pp. 75-94.

${ }^{25}$ Fernández Jiménez, Antonia, Pilar Primo de Rivera: el falangismo femenino, Madrid, Síntesis, 2008; Preston, Paul, Palomas de Guerra: cinco mujeres marcadas por el enfrentamiento bélico, Barcelona, Plaza \& Janés, 2001, pp. 21-96.

${ }^{26}$ Ofer, Inbal, Señoritas in Blue. The Making of a Female Political Elite in Franco's Spain, Sussex, Sussex Academic Press, 2009, p. 30.

${ }^{27}$ Ideal, 5 de marzo de 1937, p. 7.
} 
participaban mujeres ligadas a órdenes religiosas. Esto produjo que en la movilización y en muchas de las funciones asistenciales y educativas que se desempeñaban rivalizaran unas y otras en la guerra y, más tarde, durante todo el franquismo ${ }^{28}$.

Y en tercer lugar, hasta 1939 la labor asistencial quedó igualmente dividida entre las diferentes organizaciones femeninas y de beneficencia dentro del espectro fascista. La mayor organización social de estas, Auxilio de Invierno, se encontraba en manos de Mercedes SanzBachiller, fuera del control total de la Sección Femenina. Al ser esta una de las instituciones más importantes para despertar las simpatías al régimen, hizo que esta rivalizara con Pilar Primo de Rivera por ser la “mujer del régimen”, lo que lastró el objetivo de que la organización femenina franquista fuese capaz de controlar todas las organizaciones y la acción de la mujer en España ${ }^{29}$.

A pesar de que la Unificación debía suponer una asociación armónica de todas las organizaciones femeninas, se puede incidir en que no se alcanzaron plenamente los objetivos. La Sección Femenina no pudo aglutinar toda la movilización femenina durante la Guerra Civil debido a las divisiones ideológicas entre las representantes de cada signo político y las mujeres movilizadas bajo estos. Hecha esta consideración, sí hay que admitir que tuvo dos efectos capitales. Básicamente, consiguió integrar a muchas más mujeres bajo el mando de la Sección Femenina, y con ello logró que esta tuviese un mayor peso hegemónico a la hora de competir con las otras organizaciones de mujeres que continuaron funcionando. Esto supuso finalmente el encumbramiento de la Sección Femenina como la organización femenina predilecta del régimen y de gran parte de la sociedad española.

\subsection{La conscripción de las mujeres}

Conjuntamente, muchas mujeres fueron movilizadas a través de otras estructuras que no necesariamente comportaban la afiliación a la Sección Femenina. Pese a que en su vida cotidiana podían colaborar de muchos modos con el régimen franquista, se buscaron otros medios para movilizar a las mujeres de un modo gratuito. A partir del "Decreto 378", promulgado el 7 de octubre de 1937, se constituyó bajo el control de Auxilio Social uno de los instrumentos más significativos para la movilización de la mujer durante estos años: el Servicio Social de la Mujer $^{30}$.

Este se encargaría del encuadramiento de mujeres de entre los diecisiete y treinta y cinco años de edad para permitirles, por medio de la educación y el servicio en las instituciones del régimen durante un periodo fraccionado de seis meses, promocionar social y políticamente al

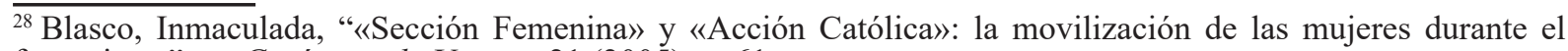
franquismo", en Gerónimo de Uztariz, 21 (2005), p. 61.

${ }^{29}$ Orduña, Mónica, El Auxilio Social (1936-1940). La etapa fundacional y los primeros años, Madrid, Escuela Libre Editorial, 1996, pp. 202-208; Alfonso Sánchez, José Manuel y Laura Sánchez Blanco, "Las mujeres del nacional-sindicalismo. Poder y rivalidad entre Pilar Primo de Rivera y Mercedes Sanz Bachiller", en Historia de la educación, 27 (2008), pp. 433-455.

${ }^{30}$ Vid. Orduña, Mónica, El Auxilio Social... op. cit., pp. 177-208; Rebollo, Pilar, El Servicio Social de la Mujer en la provincia de Huesca (1937-1978), Huesca, Instituto de Estudios Altoaragoneses, 2003.
} 
obtener una serie de "privilegios" que les brindaba el estado franquista como poder conseguir los certificados obligatorios para ejercer una profesión, acceder a empleos públicos dentro del Estado o desempeñar cargos dentro de FET de las $\mathrm{JONS}^{31}$. Al ser insuficiente el número de falangistas afiliadas a la Sección Femenina, este pudo proporcionar por otra vía nueva mano de obra femenina gratuita para tareas esenciales tras el frente como la asistencia social, el sostenimiento de las instituciones o el trabajo en los talleres, empresas o casas, siendo el trabajo dentro de Auxilio Social el espacio predilecto de las cumplidoras del Servicio Social al estar ligados institucionalmente ${ }^{32}$.

Después de ser creado a nivel nacional en 1937, el Servicio Social empezó a rodar un año más tarde en Granada. Durante 1938 se inscribieron un total de 2090 mujeres de las que 1372 procedían de la capital y 718 de las otras localidades de la provincia, siendo esta cifra su máximo histórico de afiliación. Al año siguiente, en 1939, la cifra caería a las 354 en Granada y 424 en la provincia, lo que constata una vez más el carácter de movilización de muerte de la capital y de victoria en algunos municipios de la provincia.

Gráfico 3: Realizadoras del Servicio Social en Granada (1938-1939)

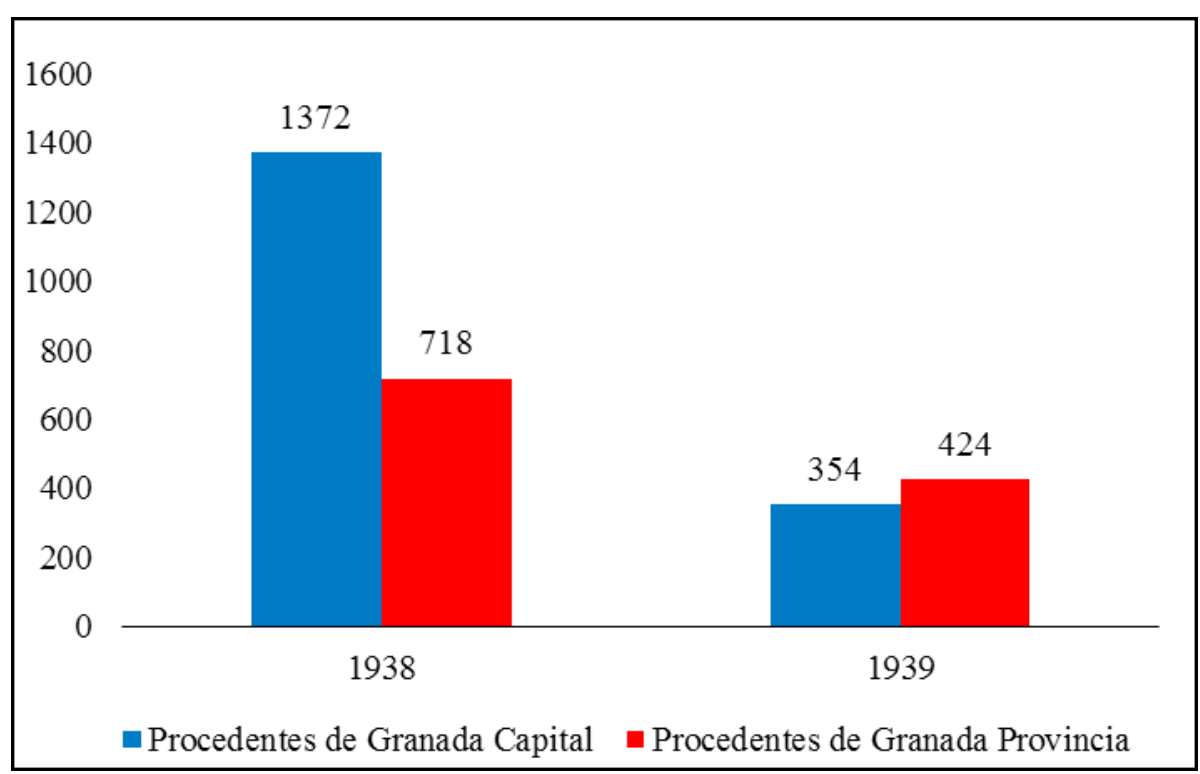

Fuente: elaboración propia a partir de AHPG, "Servicio Social..." op. cit.

Pero estas cifras de cumplidoras no fueron tan alentadoras como se presuponían ya que muchas de las mujeres que se inscribían en el Servicio Social o no lo iniciaban o no conseguían terminarlo. Podían ser dadas de baja, quedar exentas de realizarlo o trasladarse a otras partes,

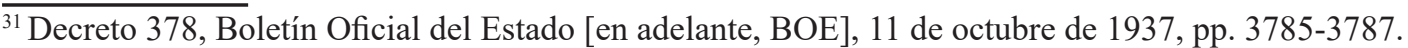

${ }^{32}$ Rebollo, Pilar, "El Servicio Social de la mujer de la Sección Femenina de Falange. Su implantación en el medio rural", en Ruiz Carnicer, Miguel Ángel y Carmen Frías (coords.), Nuevas Tendencias historiográficas en la historia local en España: Actas del II Congreso de Historia Local de Aragón, Zaragoza, Universidad de Zaragoza, 2001, p. 299.
} 
con lo que desconocemos si se consumaba realmente. Esto supuso que 622 mujeres de las 2870 totales que obtuvo su certificado de cumplidoras del Servicio Social durante los años de la contienda, cerca de un $22 \%$ no consiguieran obtenerlo ${ }^{33}$.

Al mismo tiempo, se concedieron muchas exenciones. La exención permitía a las mujeres que por diversos motivos - necesitar un trabajo para vivir, ser hija mayor de padre viudo, ser la mayor de ocho hermanos solteros, padecer un defecto físico, estar casadas, o ser viudas, hermanas o hijas de caídos - no requiriesen realizar el Servicio Social completamente o alguna de sus dos partes, previo pago de una cantidad superior y justificando el motivo ${ }^{34}$. Durante estos dos años fueron concedidas un total de 587 exenciones principalmente por motivos relacionados con la participación en las labores de retaguardia antes de la creación del Servicio Social. De ese modo, otro $20 \%$ del total de las cumplidoras se libraba, al menos parcialmente, de realizar el Servicio Social.

Gráfico 4: Exenciones del Servicio Social en Granada (1938-1939)

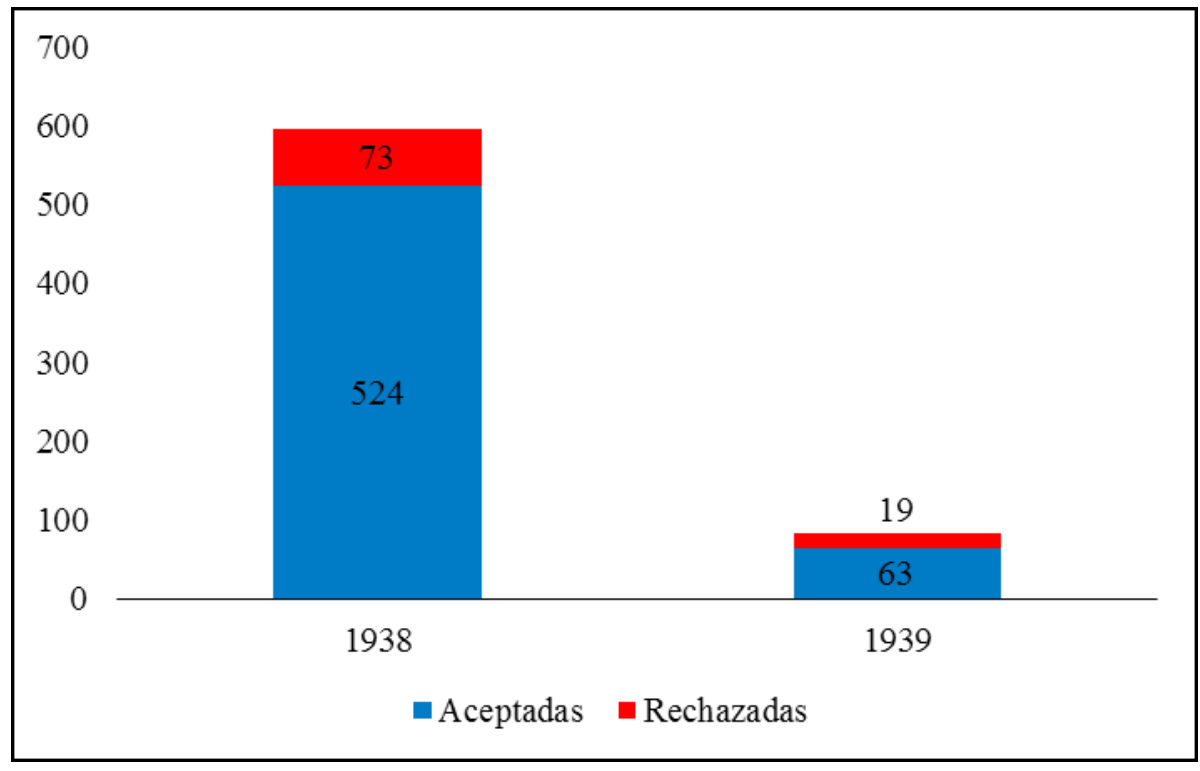

Fuente: elaboración propia a partir de AHPG, "Exenciones..." op. cit.

En suma, ni cualitativamente ni cuantitativamente el Servicio Social fue capaz de movilizar a un gran número de mujeres puesto que ni la educación que ofrecía ni el sistema de encuadramiento fueron tan atractivos ni eficaces como se presuponían. Por ello, más que para movilizar gratuitamente a otros contingentes de mujeres, sirvió como justificación jurídica y práctica de la brecha entre mujeres de las clases altas y las clases bajas, a la par que entre hombres y mujeres. Pese a ello, desde el Servicio Social se consiguió ampliar la mano de obra

\footnotetext{
${ }^{33}$ AHPG, "Exenciones (1938-1978)", sig. 8431.

${ }^{34}$ Decreto 378 ... op. cit., p. 3786.
} 
femenina en algunos de los hospitales y de las diferentes instituciones dependientes de Auxilio Social diseminadas por la provincia, al igual que se fue perfilando y poniendo en práctica la política formativa de gran parte de las futuras "mujeres azules" del franquismo.

\section{2. "En la España Nacional las mujeres no combaten con las armas en la mano": el papel de la Sección Femenina en la zona franquista}

Una vez trazados los cauces y los mecanismos que se desarrollaron para la movilización femenina debemos preguntarnos cómo y dónde colaboraron las mujeres de la Sección Femenina y hasta qué punto fue sustancial la ayuda prestada en pos de la "Victoria" de Franco. Previamente, es esencial señalar que las prácticas y los apoyos de las mujeres estaban ordenados bajo la idea de que su lugar era la retaguardia. Mientras, los hombres lucharían en la vanguardia. Sobre la diferenciación sexual y de género se dividía el espacio social. Las capacidades de cada uno y sus acciones cotidianas debían de ser trasladadas a la guerra. Por este motivo, los cometidos asignados a cada género, atendiendo a sus condicionantes "biológicos" y "tradicionales", no debían compartirse pues su trasgresión comprometía a las identidades de mujeres y hombres ${ }^{35}$. El objetivo esencial de esto era crear y consolidar la imagen de que antes y después de la "cruzada franquista" la agencia femenina debía confinarse siempre en la retaguardia: durante la guerra tras el frente y en la posguerra en el hogar.

La labor de la Sección Femenina granadina estuvo profundamente condicionada por al guerra. El radio de actuación dependió siempre de la situación que se vivía en los frentes y de la velocidad con la que se pudo actuar desde las instituciones para estabilizar y consolidar el poder franquista. A la vez, esta estaba constreñida por las limitaciones humanas y materiales para respaldar las nuevas células locales que surgían espontáneamente o para articular su creación y desarrollo. Por ejemplo, durante la guerra las falangistas granadinas solamente contaron con un vehículo cedido por el príncipe de Asturias, Don Alfonso de Borbón, con el que visitaron frentes y organizaron secciones femeninas en otras localidades ${ }^{36}$. Esto produjo que fuera en distintos compases su constitución y extensión a lo largo de la provincia.

En general, el triunfo del franquismo no puede ser completamente entendido sin atender a la acción de las mujeres movilizadas por medio de la Sección Femenina que empujaron como pudieron, y se les permitió, a Falange y al régimen durante la contienda ${ }^{37}$. Toda esta

\footnotetext{
${ }^{35}$ Blasco, Inmaculada, Armas femeninas ... op. cit., p. 40.

${ }^{36}$ AHPG, "Historia de la..." op. cit.

${ }^{37}$ Del Rincón, María Fernanda, "Mujeres azules en la Guerra Civil", en Estudis d'Historia Contemporania del Pais Valencia, 7 (1986), pp. 45-68; Seidman, Michael, The Victorious... op. cit.
} 
ayuda se canalizó básicamente apoyando en muchos aspectos al ejército en el frente de batalla, manteniendo y organizando estructuras institucionales fundamentales como la beneficencia en la retaguardia, e iniciando el proyecto educativo y disciplinario franquista que sería instrumentalizado sobre muchas mujeres. Actuaciones muchas veces invisibilizadas y que son imprescindibles para comprender el desarrollo de la Guerra Civil y los inicios del franquismo.

\subsection{El apoyo a la vanguardia}

Aunque la vanguardia quedó teóricamente limitada para los hombres, las mujeres falangistas muchas veces traspasaron esa frontera. La primera labor de la mujer, aunque la mayor parte de su acción quedaba reducida a la retaguardia, era la de asistir a los combatientes. La higiene y la vestimenta eran imprescindibles para la supervivencia en el frente ante las enfermedades y el frío del invierno. Por ello se organizaron lavanderos donde se preparaba la ropa de los soldados para ofrecérsela cada cierto tiempo limpia y cosida ${ }^{38}$. Al mismo tiempo, también se establecieron talleres, que funcionaban en el local de la Sección Femenina o en las mismas casas de muchas de ellas, en los que se arreglaban las camisas, se confeccionaba uniformes, se hacían vendas o se tricotaban prendas de abrigo. Se enfrentaban, sin embargo, continuamente en ellos a las limitaciones que imponía la escasez de medios y materiales como la tela azul.

De la misma forma, con periodicidad, las muchachas de la Sección Femenina visitaban el frente para mejorar la "moral" de los soldados y como reclamo propagandístico del régimen ${ }^{39}$. En estos encuentros preparaban el almuerzo para los soldados, les ofrecían su "cariñosa compañía" y les entregaban todo tipo de bienes, como alimentos en frío o tabaco, a fin de hacerles más llevadera la vida en las trincheras ${ }^{40}$. Mientras tanto se inició otro tipo de servicios de "apoyo moral" a los soldados como el de las "madrinas de guerra". Previamente practicado en otros enfrentamientos armados internacionales, desde la prensa se instaba a las mujeres para que iniciasen una correspondencia epistolar con los soldados que lo solicitasen. Este carteo entre unos y otros servía para que los soldados "luchasen contra la soledad" e incluso para que se iniciase una relación cuando terminara la guerra, reproduciendo el marco afectivo y sentimental heteronormativo al que el franquismo daba cobijo ${ }^{41}$.

De igual modo, como enfermeras, representaban otra de las imágenes más valoradas de la Sección Femenina. La división institucional que produjo el conflicto y las deficiencias sanitarias

\footnotetext{
${ }^{38}$ Algunos de los principales lavaderos de ropa en los frentes granadinos estaban en Puerto Lope, Pinos Genil, Huetor Santillán, Lanjarón, Órgiva, Fargue, Güéjar Sierra, Pinos Puente y Víznar. Archivo General de la Administración [en adelante, AGA], “Consejos Nacionales. Sección Femenina de F.E.T. de las J.O.N.S. (Libro primero)”, Sección Femenina, sig. 23/27 406-27.407, Gr 6, núm. 7, caja 1.

${ }^{39}$ Seidman, Michael, The Victorious ... op. cit., 163-164.

${ }^{40}$ Ideal, 18 de mayo de 1937 , p. 7 y 29 de mayo de 1937, p. 4.

${ }^{41}$ De Ramón Carrión, Manuel y Carmen Ortiz, Madrina de guerra. Cartas desde el frente, Madrid, La Esfera de los Libros, 2003; de Ramón Carrión, Manuel, "Las madrinas de guerra en la Guerra Civil", en Bulletin hispanique, vol. 118, 1 (2016), pp. 157-174.
} 
que existían antes y durante este hacían muy importante la asistencia sanitaria en el frente y detrás de este en una España azotada por la enfermedad y la muerte. ${ }^{42}$ Los laboratorios, equipos quirúrgicos o de transfusión de sangre y las consultas requirieron de enfermeras y asistentes que ayudaran en esta labor tan importante para el sostenimiento de la vida social y militar. Por ello se creó desde el Estado el Frente de Hospitales como órgano que se encargaría de organizar la asistencia sanitaria femenina en la zona sublevada hasta el final de la guerra.

Desde este se plantearon dos problemas principales. Por un lado, estaba constituido independientemente y controlado en su mayoría por mujeres procedentes del espectro carlista, convirtiéndose hasta 1937 en un espacio más en la disputa para que el falangismo y la Sección Femenina fueran las organizaciones políticas dominantes ${ }^{43}$. Por otro lado, la falta de mujeres especializadas y preparadas para el desempeño de servicios sanitarios era una realidad en provincias como Granada. A causa de esta deficiencia se realizaron cursos rápidos de enfermería, de aproximadamente treinta días, para subsanar esta demanda y capacitar a muchas afiliadas de la Sección Femenina, y se llegó a titular en ellos al menos sesenta enfermeras granadinas que luego pudieron participar dentro de las instituciones sanitarias franquistas, como el Hospital de Sangre del Refugio donde trabajaban en torno a treinta y nueve de ellas ${ }^{44}$.

Además, enfermeras y afiliadas de la Sección Femenina se encargaron de la labor de alentar a la población, y sobre todo a las mujeres, a "prestar su sangre por la patria". Las mujeres recluidas en la retaguardia fueron probablemente durante la guerra las mayores donantes de sangre que tuvo el nuevo régimen franquista ${ }^{45}$, exhibiéndose a estas con una generosidad que "llega a límites insospechados, pues hay entre ellas quienes, después de haber perdido al marido, padre o hijos, ofrecen su sangre, sabiendo que ha de servir muchas veces para la transfusión de heridos rojos recogidos por nuestras ambulancias" ${ }^{46}$. Todas estas tareas fueron igualmente aprovechadas como reclamo propagandístico para mejorar la imagen del régimen, conseguir más apoyos y movilizar a más mujeres.

\subsection{El sostenimiento de la retaguardia}

Otra de las labores más visibles y necesarias de las falangistas fue la asistencia social y la beneficencia. Durante la Guerra Civil, y aún más en la posguerra, Granada fue un "mundo de miseria”. El hambre, el paro y la pobreza formaban parte de la cotidianeidad de la gran mayoría

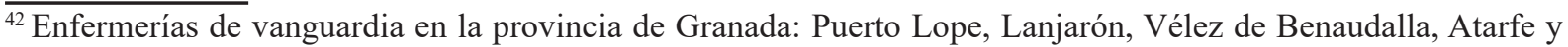
Siena. AGA, "Consejos Nacionales..." op. cit.

${ }^{43}$ En Granada la división era patente en el control mismo de los hospitales: el de San Antón, que era un Hospital de Sangre, estaba controlado por Falange; el del Hotel Palace pertenecía a las Tradicionalistas; y el Hospital San Francisco, emplazado en la Alhambra, poseía un carácter general. Real Academia de la Historia [en adelante, RAH], Archivo Documental "Nueva Andadura", núm. 35, doc. 3.

${ }^{44}$ Ideal, 14 de septiembre de 1937, p. 5 y 20 de febrero de 1938, p. 10.

${ }^{45} A B C, 3$ de mayo de 1937, p. 25.

46 “ESTE ES EL EJÉRCITO: Sanidad”, en Vértice, julio y agosto de 1937.
} 
de granadinos y granadinas ${ }^{47}$. Por ello, ante la creación del nuevo aparato gubernamental y la tensión social violentada por estas circunstancias estructurales, fue necesario que se desplegase una política social que contribuyese paliar algunos de los problemas de la población. Para conseguirlo una de las armas más eficaces con las que se contaron fue el Auxilio Social ${ }^{48}$.

El 29 de octubre de 1936 fue fundado el Auxilio de Invierno en Valladolid por Mercedes Sanz-Bachiller junto con el que sería su futuro esposo, Javier Martínez de Bedoya, siguiendo los modelos alemanes de la Nationalsozialistische Volkswohlfahrt, desde 1933 la organización asistencial nazi, y Winterhilfswerk, encargada de la asistencia en los duros meses de invierno ${ }^{49}$. Los comedores del Auxilio de Invierno empezaron a brotar por toda la España rebelde y asistían principalmente a huérfanos y a aquellos en las circunstancias más sobrecogedoras, sirviendo raciones y ofreciendo, cuando había medios, asistencia médica. Ya en 1937, cuando pasó a llamarse Auxilio Social, empezó a constituirse como la institución predilecta del franquismo al encargarse de su "justicia social". ${ }^{50}$

En la ciudad de Granada, la inauguración del primer comedor social del Auxilio de Invierno se realizó el 1 de abril de ese mismo año. A partir de aquí comenzó el goteo de inauguraciones en la capital y la provincia conforme la guerra avanzaba, las arcas recaudatorias crecían a duras penas y se iban sometiendo otros municipios. A pesar de que con los fondos e instalaciones que se disponían resultaba imposible ayudar a todas las bocas hambrientas que se iban agolpando a las puertas de los comedores y en las colas de los repartimientos, las mujeres de la Sección Femenina se encargaron personalmente de la mayor parte de la financiación del Auxilio Social. Con el paso del tiempo se fueron desarrollando más acciones para obtener fondos: difundiendo propaganda, organizando tómbolas y sorteos, o saliendo a las calles a "cuestar" a la población, intercambiando donativos por insignias y banderas para la obra del Auxilio Social ${ }^{51}$.

Además, Auxilio Social debía estar siempre en marcha para construir adhesión entre los granadinos $^{52}$. Por ello se aprovechaban algunas fechas y ocasiones especiales para el calendario franquista, como el día de los Caídos, la Nochebuena o la visita de alguna personalidad del régimen para repartir alimentos como azúcar, pan, viandas o golosinas, que serían recibidas con “entusiasmo" por los granadinos y granadinas necesitados. Por ejemplo, en octubre de 1937,

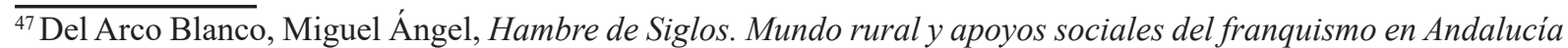
Oriental (1936-1951), Granada, Comares, 2007, pp. 291-328.

${ }^{48}$ Carasa, Pedro, "La revolución nacional-asistencial durante el primer franquismo (1936-1940)", en Historia Contemporánea, 16 (1997), pp. 94-95.

${ }^{49}$ Burleigh, Michael, The Third Reich. A New History, Londres, McMillan, 2000, pp. 206-228; de Witt, Thomas,

"«The Struggle against Hunger and Cold»: Winter Relief in Nazi Germany, 1933-1939", en Canadian Journal of History, vol. 12, 3 (1978), pp. 361-381. DOI: https://doi.org/10.3138/cjh.12.3.361.

${ }^{50}$ Sobre los inicios de Auxilio Social, véase: Orduña, Mónica, El Auxilio Social... op. cit., pp. 51-77; Preston, Paul, Palomas de guerra ... op. cit., pp. 21-96; Cenarro, Ángela, La sonrisa de Falange. Auxilio Social en la guerra civil y en la posguerra, Barcelona, Crítica, 2006, pp. 1-27.

${ }^{51}$ AHPG, "Historia de la..." op. cit.; Orduña, Mónica, "Donativos nacionales e internacionales a Auxilio Social", en Bullón de Mendoza, Alfonso y Luis Eugenio Togores (eds.), Revisión de la guerra civil española, Madrid, Actas, 2003, pp. 1083-1093.

${ }_{52}$ Molinero, Carme, La captación de las masas. Política social y propaganda en el régimen franquista, Madrid, Cátedra, 2005, pp. 163-169.
} 
con motivo de la visita de Pilar Primo de Rivera, se inauguraron nuevos comedores como el de Motril y se repartieron raciones especiales en estos $^{53}$.

Simultáneamente, para el falangismo el mundo rural era también esencial a la hora de lograr apoyos y construir su imaginario colectivo. Todos los problemas suscitados de la conflictividad agraria durante la Segunda República querían ser atajados por medio de políticas agrarias proteccionistas para conseguir "elevar a todo trance el nivel de vida del campo, vivero permanente de España" ${ }^{\prime 4}$. Desde el falangismo se hablaba en estos años de que se tenía que levantar "la aldea de Falange", redistribuyendo la tierra, mejorando la producción y las condiciones de la gente, y ofreciendo "una fuerte ofensiva de sanidad y particularmente una política del niño, una política de la infancia" ${ }^{55}$.

La Sección Femenina, inspirada en estas ideas joseantonianas, tomó el comedido de realizar una ambiciosa campaña por mejorar la vida rural de las mujeres y sus familias. Prestando para ello sus manos en las diferentes labores del campo, ofreciendo alimentos y bienes a los que no podía acceder la población, transportando la medicina y la sanidad a los lugares donde nunca llegaban, ni habían llegado, y llevando la doctrina falangista a las mujeres para adherirlas al partido, alfabetizarlas, enseñarles el desempeño de labores e instruirles. Para ello la regiduría de la Hermandad de la Ciudad y del Campo fue constituida en 1937 a causa del desplazamiento de muchos hombres a luchar en el frente y a la cada vez mayor presencia de la mujer en el campo. La creciente falta de mano de obra y la necesidad de organización, protección y disciplina de las campesinas o de las amas de casas rurales movieron a la creación de los Servicios de Trabajo en el Campo y Trabajo en la Ciudad, que al poco tiempo acabaron fusionados en la Hermandad ${ }^{56}$.

Esta se movió desde el principio en la formación de muchas falangistas que servirían como trabajadoras rurales, maestras o visitadoras de la Hermandad, para prepararlas en sus nuevos cometidos e instalándolas al mismo tiempo para que llevasen la doctrina de Falange a las gentes del campo. Los primeros cursos provinciales empezaron a realizarse en 1937, fecha temprana debido a las circunstancias eminentemente rurales de la provincia ${ }^{57}$, y continuaron hasta después de la guerra ante un mundo rural cada vez más desprovisto. Entre las primeras labores que se emprendieron en la provincia se intentó movilizar a unas pocas mujeres a participar en el trabajo agrario o a colaborar en las casas de los trabajadores del campo realizando tareas de limpieza y cuidado de los niños, sustituyendo a las madres que fuesen a faenar.

En la retaguardia, la labor de las mujeres bajo los muros de Auxilio Social fue indispensable para asistir a la ascendiente masa de granadinos que estaban necesitados de algún tipo de sustento por causa de la guerra. Ni mucho menos esta beneficencia fue suficiente para solventar

\footnotetext{
$\overline{{ }^{53} \text { Ideal, } 6 \text { de octubre de 1937, p. } 2 .}$

${ }^{54}$ Véanse los puntos programáticos del 17 al 20: Primo de Rivera, José Antonio, Obras Completas, Madrid, Delegación Nacional de la Sección Femenina de FET de las JONS, 1942, pp. 339-344.

${ }^{55}$ VV. AA., Dolor y memoria de España. En el segundo aniversario de la muerte de José Antonio, Barcelona, Jerarquía, 1939, pp. 40-41.

${ }_{56}^{5}$ Marías, Sescún, "Por España ... op. cit., p. 65.

${ }^{57}$ Ideal, 5 de septiembre de 1937, p. 11.
} 
la problemas que existían entre toda la población necesitada, pero sí permitió mitigar parte de la miseria de determinados colectivos vulnerables y ofrecer una imagen más indulgente del "Nuevo Estado". Del mismo modo, hay que señalar que la acción de la Sección Femenina a lo largo y ancho del campo granadino no llegó a ser lo suficientemente destacable como para poder desplegar sus proyectos o solventar algunas de las acuciantes deficiencias que se vivían, por lo que muchas veces las iniciativas de la Hermandad de la Ciudad y del Campo quedaban solo sobre el papel.

\subsection{La conversión de la mujer}

La Sección Femenina inició en este momento su principal labor: educar a la mujer. Para ello, puso todo su interés tanto en construir unos nuevos discursos y modelos de feminidad nacionales como en desplegar instituciones, programas y herramientas formativas propias para el desarrollo de una biopolítica franquista ${ }^{58}$. La educación y el trabajo eran cuestiones fundamentales y por ello se implementó la acción de formar tanto a las mandos que debían tomar las riendas del cuerpo social femenino como a las "flechas" que serían las futuras afiliadas de la organización.

Desde la Segunda República se tuvo en cuenta la educación de los primeros mandos, pero fue desde la Guerra Civil cuando se comenzó la creación de la mayoría de las regidurías de encuadramiento ${ }^{59}$, se iniciaron cursos formativos y otro tipo de actividades para educarlas completamente en sus desempeños públicos y privados durante la mayor parte de su vida útil para el partido y el régimen ${ }^{60}$. En cierto sentido el objetivo de la Sección Femenina era ordenar todos los aspectos de la educación y la vida de las mujeres para hacer de ellas esposas, madres y falangistas. Toda la vida de la mujer debía pasar por un proceso de disciplina y adoctrinamiento para que fueran ellas las que llevaran el orden que propugnaba el franquismo a la realidad femenina.

Y en esta educación no solo se ponía un gran interés en el aspecto doctrinario, sino que se pretendía disciplinar al mismo tiempo sus cuerpos y sus prácticas: la mujer falangista debía ser construida hasta en el gesto. Para ello, se fomentó entre ellas la cultura de la Educación Física con la que se podría amoldar sus actitudes y costumbres, trasmitir los valores del nuevo régimen por medio del deporte, incluso modular las formas y los movimientos fisiológicos a fin de constituir un ideal de mujer. Sus cuerpos tenían que ser resistentes a los efectos de la guerra y cumplir con su "función vital" como prolíficas madres ${ }^{61}$.

\footnotetext{
${ }^{58}$ Cayuela, Salvador, Por la grandeza de la patria. La biopolítica en la España de Franco, Madrid, Fondo de Cultura Económica, 2014, pp. 172-185.

${ }^{59}$ Ideal, 7 de octubre de 1937, p. 2.

${ }^{60} \mathrm{RAH}$, Archivo Documental "Nueva Andadura", núm. 4, docs. 1-4.

${ }^{61}$ Morcillo, Aurora, En cuerpo y Alma. Ser mujer en tiempos de Franco, Madrid, Siglo XXI, 2015, pp. $273-280$.
} 
En Granada se organizaron desde 1937 algunas actividades deportivas o cursillos para formar a alumnas y profesoras. La insuficiencia de estas últimas era un problema real en la provincia por lo que se organizó el primer Cursillo de Educación Física Femenina en octubre de 1938 para formarlas. En general, se buscaba iniciar y completar la educación femenina aunque el contexto de pobreza generalizado lo impidiese. La falta de instructoras, instalaciones y materiales dificultaba que todos estos proyectos pudiesen ejecutarse como Pilar Moliné y otras dirigentes provinciales desearan ${ }^{62}$. Una problemática que se mantuvo durante todo el primer franquismo. La Regiduría Provincial de Educación Física se crearía ya durante 1938, organizándose desde esta todo tipo de cursos sobre cultura física, ejercicios para las muchachas, juegos y algunos deportes, en lugares como la plaza de toros de la capital. Por medio de la práctica debían aprender a respetar la jerarquía, la competitividad, el autocontrol y el comedimiento, "a ganar sin petulancias y a perder sin despecho"63.

No debe desdeñarse la labor educativa general que se inició por la Sección Femenina en este momento. Muchas de las propuestas y medidas educativas contribuyeron, a pesar de las consecuencias ideológicas que comportaban, en la implementación de la alfabetización y la educación básica de las mujeres de las clases más frágiles y de las zonas periféricas al proceso de alfabetización. Se fomentaron iniciativas como la creación de escuelas nocturnas urbanas para mujeres en las que se les enseñaban a leer y escribir, matemáticas, religión y otro tipo de labores. Más adelante, se crearían los cuerpos de las Divulgadoras Sanitario-Rurales y las Cátedras Ambulantes que llevarían esta educación en temas como la salud y la higiene al campo. La educación falangista comenzaría a enseñarles que sus vidas estaban consignadas al hogar al tiempo que propugnaba que asumir esta situación les abriría algunas ventanas de libertad, aunque fuera prácticamente imposible escapar de este destino.

\section{Conclusiones}

La Guerra Civil fue un acontecimiento cardinal para la movilización de las españolas. Pese a que durante los años de gobierno republicano las mujeres se habían adentrado cada vez más en la esfera pública, el enfrentamiento entre unos y otros motivó que muchas otras se movilizaran. Al igual que bajo la República, el "Nuevo Estado" de Franco también tuvo que valerse de la colaboración femenina para la consecución de algunos de sus objetivos en medio del enfrentamiento por lo que, para tal fin, fue imprescindible la labor de la Sección Femenina

\footnotetext{
${ }^{62}$ Entrala, José Luis, Granada sitiada, 1936-1939, Granada, Comares, 1996, pp. 107-108.

${ }^{63}$ Ideal, 10 de septiembre de 1938, p. 7.
} 
de Falange, que se encargó de articular la captación y acción de las mujeres bajo el signo nacionalsindicalista.

Es innegable el hecho de que el régimen franquista pudo movilizar a un mayor número de mujeres durante la contienda. La fuentes con las que contamos nos arrojan la imagen de una Sección Femenina con un mayor número de integrantes — durante estos años se llega a sugerir que el número de afiliadas en la ciudad de Granada se multiplicó por veinticinco y en toda la provincia se sumaron varios millares - y con una más amplia y acelerada actividad política. Indudablemente, el contexto bélico construyó y ofreció motivos al Estado sublevado y a las mujeres para tomar partido bajo el espectro derechista, muchas veces contrario. Por ello se intentó captar e integrar todos estos apoyos en una sola organización fascista, promover nuevos medios de movilización política y legitimarlos ideológicamente y a través de la cultura.

Todos los cauces con los que se contaron permitieron una participación femenina no muy extendida pero suficiente para ofrecer una notable ayuda al franquismo. Hasta hace poco no se había prestado la suficiente atención a qué es lo que pasaba detrás de los frentes de batalla, como no se había prestado previamente interés a quiénes estaban detrás de los soldados en combate. Gradualmente vamos observando el papel que tuvieron las mujeres dentro de los conflictos armados pese a que su participación directamente en el enfrentamiento armado sea inexistente o residual. Esto nos lleva a apuntar que difícilmente podríamos comprender completamente las estructuras y los mecanismos del conflicto si no tenemos en cuenta tanto las relaciones de poder existentes como las actitudes del contingente más importante de la población, las mujeres. Consecuentemente, es necesario que se vaya paulatinamente ampliando el número de investigaciones orientadas hacia estas temáticas.

Defendemos, así pues, que la acción de las mujeres falangistas tuvo un papel destacable en la Guerra Civil que no ha sido aún suficientemente reconocido y estudiado. Ya sea asistiendo a los soldados en la vanguardia o a la población en la retaguardia, la Sección Femenina contribuyó en el apoyo material y sanitario del ejército y en el desarrollo de muchas de las políticas e iniciativas sociales que permitieron generar actitudes de adhesión y consentimiento en aquellos territorios teñidos de azul. Al mismo tiempo, se pudo iniciar el proyecto educativo sobre la mujer, no sin muchas dificultades en provincias como Granada, creando y conformando el compromiso político en las afiliadas. Esto permitió ir poniendo los primeros peldaños del proyecto franquista sobre la mujer, moviéndolas a convertirse en "ángeles del hogar" o "señoritas de azul" y consolidando estas imágenes femeninas como fuentes de legitimidad de su posición social subalterna.

Movilización y participación de las mujeres de la Sección Femenina durante la Guerra Civil servirían en gran medida para probar y trazar los límites políticos que tendrían las mujeres bajo el franquismo. Desplazamientos que empujaron a una pequeña parte de ellas a intervenir en la vida pública y, finalmente, a su encierro mayoritario en la esfera privada durante la larga posguerra. 